\title{
Transaction
}

\section{Structural Study on Aromatic Poly(amic $n$-alkyl ester)s and Their Derivatives by Solid-State Imidization II. Effect of Unremoved Alkyl Chains Attached by Ether Linkage}

\author{
Katsuhiro Inomata, Sachi Shimomura, Hiroyasu Hasegawa, Marika Ogiso, \\ Hideki Sugimoto, and Eiji Nakanishi
}

Faculty of Engineering, Nagoya Institute of Technology, Gokiso-cho, Showa-ku, Nagoya 466-8555, Japan

\begin{abstract}
Rodlike aromatic copolyamides (CoPA-8), in which some octyloxycarbonyl $\left[\mathrm{H}_{(}\left(\mathrm{CH}_{2}\right)_{8} \mathrm{OC}(=\mathrm{O})-\right]$ side chains of poly(amic octyl ester) (PA-8) were substituted by octyloxy $\left[\mathrm{H}_{(\mathrm{CH}} \mathrm{C}_{8} \mathrm{O}-\right.$-] groups, were prepared. In CoPA-8, the octyl side chains were attached to the main chain by ether or ester linkage. Structure of CoPA- 8 before and after thermal and chemical imidization was investigated, and the results were compared with PA-8. Before the imidization, CoPA- 8 formed a layered structure with alternating main-chain and side-chain segregated layers. Because the ether linkage was stable against the imidization reaction, formation of imide ring occurred only at the monomer unit having octyloxycarbonyl group. After imidization at $300^{\circ} \mathrm{C}$, the octyloxy groups were removed by thermal degradation, however, the layered structure was still maintained as suggested by wide-angle X-ray diffraction pattern. Effectiveness of the octyl chains attached by ether linkage in order to maintain the layered structure has been discussed.
\end{abstract}

(Received 3 December, 2007 ; Accepted 26 May, 2008)

\section{Introduction}

In the previous paper (Part I of this series), we have investigated solid-state imidization of aromatic poly(amic $n$-alkyl ester)s (PA- $n$ ) having long alkyl side chains [1]. By thermal and chemical imidization, alkyl alcohols were eliminated and PA- $n$ changed to poly( $p$-phenylene pilomellitimide) (PPPI). Wide-angle X-ray diffraction (WAXD) measurements revealed that PA- $n$ formed a layered structure, in which the aromatic main chains and aliphatic side chains segregated separately to form alternating layers [2-6]. If the imidization reaction and alkyl chain elimination occur with maintaining the layered structure, the alkyl chain layer would change to a microvoid or cavity, as the result, mesoporous polyimide with regularly-ordered cavities was expected. However, as concluded in the previous paper, the layered structure of PA- $n$ was hardly maintained, and destroyed when more than $40 \%$ alkyl chains were removed from the sample $[1,6]$. During the imidization reaction, some sharp WAXD reflections assigned to PPPI crystalline lattice were observed in early stage, suggesting a strong segregation strength of PPPI chains.

With considering the above conclusions, in this work, we have prepared copolyamides in which some alkyl chains were attached to the main chain via ether linkage (CoPA-8 in Fig. 1). Because the alkoxy group is stable against the imidization reaction, the reaction occurs only at the monomer unit where the alkyl chain is attached via the ester linkage. As the results, even in a completely imidized sample, some alkyl chains will be still attached to the main chain randomly, and they are expected to prevent the destruction of the layered structure. As performed in the previous paper, structure change after the solid-state thermal and chemical imidization reaction was investigated by Fourier transform infrared (FT-IR) spectroscopy, WAXD, and density measurements.

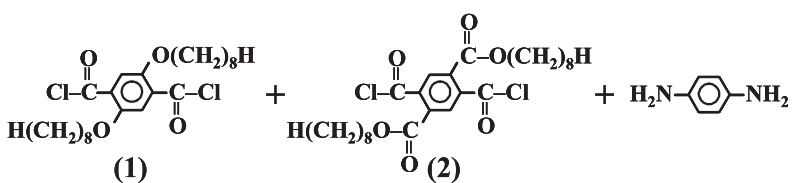

(1)
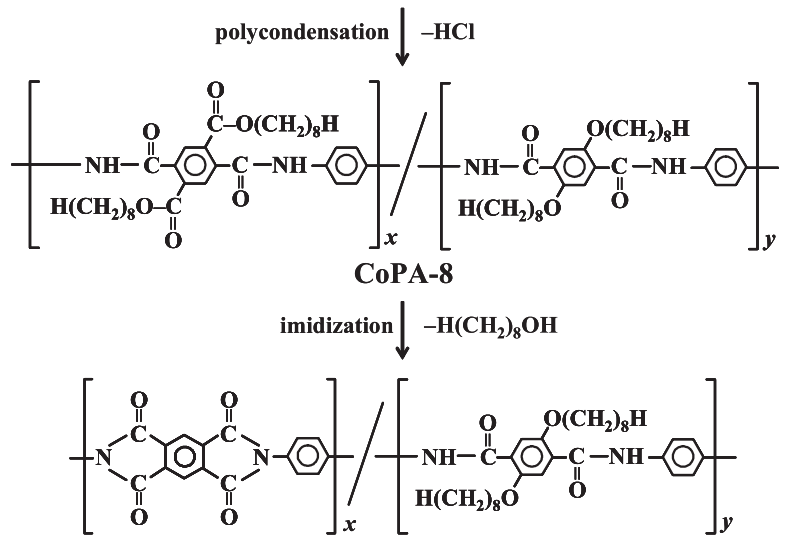

Fig. 1 Preparation scheme and chemical structure of CoPA-8. 


\section{Experimental}

Terephthalic acid having alkoxy chains was synthesized according to ref 7. Diethyl 2,5-dihydroxy terephthalate $(0.03 \mathrm{~mol})$ and 1-bromooctane $(0.15 \mathrm{~mol})$ were reacted in acetone $(180 \mathrm{ml})$, in the presence of potassium carbonate $(0.06 \mathrm{~mol})$, at $80^{\circ} \mathrm{C}$ for $24 \mathrm{~h}$. After the reaction, the precipitates were filtered off, and acetone was evaporated under the vacuum. Thus obtained diester, diethyl 2,5-bis (1-octyloxy) terephthalate, was recrystallized from ethanol.

$2.4 \mathrm{mmol}$ of the diester was dissolved in $2.5 \mathrm{ml}$ of ethanol, $2.4 \mathrm{mmol}$ of potassium hydroxide dissolved in $3.1 \mathrm{ml}$ of water was added, and the solution was refluxed for $45 \mathrm{~min}$. After adding an additional ethanol $(0.75 \mathrm{ml})$, refluxing was continued for $4 \mathrm{~h}$. After the reaction, the solution was cooled in ice water bath, and neutralized by aqueous hydrogen chloride. The precipitated diacid, 2,5bis(1-octyloxy)terephthalic acid, was separated by filtration, and recrystallized by using ethanol/water mixed solvent $(4 / 1 \mathrm{v} / \mathrm{v})$.

In order to synthesize acid chloride, the diacid was added excess thionyl chloride (4 molar equiv.) and a drop of $N, N$-dimethylformamide, and refluxed for $2 \mathrm{~h}$. After the reaction, the excess thionyl chloride was removed by distillation under reduced pressure, and 2,5-bis(1octyloxy)terephthaloyl chloride (1 in Fig. 1) was obtained after drying in vacuum.

2,5-bis(1-octyloxycarbonyl)terephthaloyl chloride (2) was prepared according to the previous paper $[1,6]$.

Random copolymerization of $\mathbf{1}, \mathbf{2}$, and 1,4diaminobenzene was conducted as follows. $5 \mathrm{mmol}$ of the mixtures of 1 and 2 with their molar ratio of $5: 5,7: 3$, or 9: 1 was dissolved in $10 \mathrm{ml}$ benzene, and $12 \mathrm{mmol}$ of propyrene oxide was added. Under flow of dry nitrogen, 5 mmol of 1,4-diaminobenzene dissolved in $10 \mathrm{ml}$ of hexamethylphosphoric triamide was added dropwise, and stirred for $24 \mathrm{~h}$ at room temperature. After the polycondensation reaction, the solution was poured into methanol. The precipitated copolyamide was filtered off, and dried in vacuum.

Thermal imidization of the copolyamide was conducted by heating the sample under reduced pressure, and chemical imidization was conducted by soaking the sample in pyridine or pyridine/toluene mixed solvent. Details of the imidization procedures and measurements of thermogravimetry analysis (TGA), FT-IR, WAXD, and bulk density were described in the previous paper $[1,6]$.

\section{Results}

\subsection{Structure of CoPA-8}

The molar ratio of $\mathbf{2}$ and $\mathbf{1}$ for copolyamides prepared in this study was $5: 5,7: 3$, and $9: 1$. Hereafter, these copolyamides will be designated as CoPA-8-5/5, $-7 / 3$, and $-9 / 1$, respectively. Therefore, in CoPA-8-9/1, ca. $10 \mathrm{~mol} \%$ of alkyl chains were attached via ether bond, and ca. $90 \mathrm{~mol} \%$ of monomer unit can change to imide ring by the imidization.

In Fig. 2b, IR spectrum of CoPA-8-5/5 is shown and compared with that for PA-8 (Fig. 2a). Because of the substitution from ester bond to ether bond, $\mathrm{C}=\mathrm{O}$ stretching mode for ester group $\left(1726 \mathrm{~cm}^{-1}\right)$ reduced its intensity, and C-O stretching mode for ether group can be observed around $1200 \mathrm{~cm}^{-1}$.

In Fig. 3a, WAXD photograph for CoPA-8-5/5 is indicated. Sharp and intense reflection, indicated by an arrow, was observed at smaller angle region on the equatorial line and its $d$-spacing was evaluated as 1.49 $\mathrm{nm}$. Additional weak second-order peak was observed, suggesting that these copolymers formed the layered structure with alternating side-chain and main-chain segregated layers as shown in the previous paper [1]. A reflection at $1.2 \mathrm{~nm}$ on the meridional line corresponds to the repeating distance along the main chain was also recognized. It should be noted that the layer spacing for PA-8 was $1.16 \mathrm{~nm}$ [1], which was smaller than $1.49 \mathrm{~nm}$ for CoPA-8-5/5, although the length of side chain for the ether linkage ( $\left.\mathrm{R}-\mathrm{O}^{-}\right)$was shorter than that for the ester linkage ( $\mathrm{R}-\mathrm{O}-\mathrm{C}(=\mathrm{O})-$ ). This difference may be caused by a different packing manner of polymer chains in the respective layered structure. WAXD pattern for CoPA-8$7 / 3$ and CoPA-8-9/1 was rather broad as shown in Fig. 3 b. The $d$-spacing for their innermost reflection was 1.49 and $1.48 \mathrm{~nm}$, respectively, suggesting that CoPA-8-7/3 and $-9 / 1$ may also exhibit the layered structure with similar packing manner as CoPA-8-5/5.

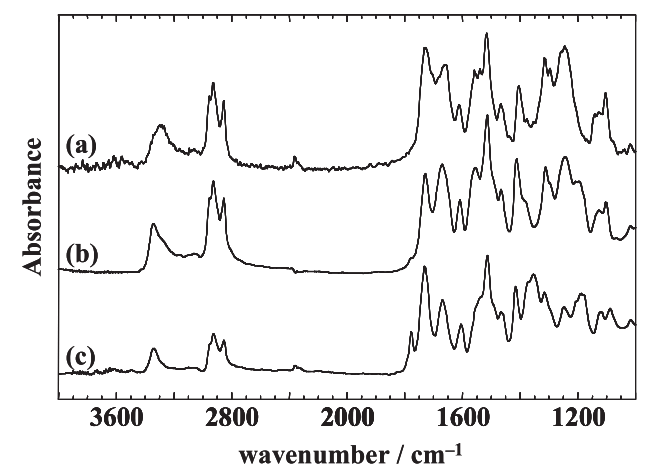

Fig. 2 FT-IR spectra for (a) PA-8, (b) CoPA-8-5/5, and (c) thermally imidized CoPA- $8-5 / 5$ at $250^{\circ} \mathrm{C}$. 


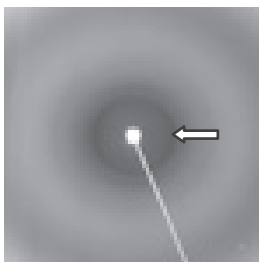

(a)

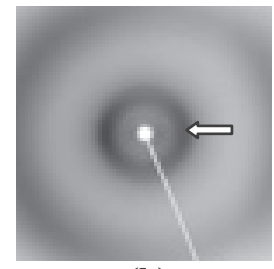

(b)
Fig. 3 WAXD photographs for (a) CoPA-8-5/5 and (b) CoPA-8-9/1. The normal of the film was placed in the horizontal direction, and the incident Xray beam was parallel to the film surface.

\subsection{Thermal and chemical imidization}

In Fig. 4, TGA curves for CoPA-8 are compared with PA-8. In PA-8, the sample weight started to decrease about $200^{\circ} \mathrm{C}$, and above $350^{\circ} \mathrm{C}$, the curve revealed plateau at remained weight of $\sim 52 \%$. This value agreed with molecular weight change from PA-8 to PPPI, and the derived PPPI was thermally stable till $550^{\circ} \mathrm{C}$. In CoPA-8$9 / 1$, the weight reduction started about $200^{\circ} \mathrm{C}$, and slope of the curve was decreased at once around $300^{\circ} \mathrm{C}$, and further decrease in weight was observed around $400^{\circ} \mathrm{C}$. This two-step reduction in weight was more clearly observed in CoPA-8-7/3 and CoPA-8-5/5. The first reduction in weight can be assigned to the imidization and removal of octanol from the sample, because the weight remaining percentage around $350^{\circ} \mathrm{C}$ can be explained by their molecular structure. With considering that the final polymer contains less thermally stable units than PPPI, further decrease in weight above $400^{\circ} \mathrm{C}$ may correspond to thermal degradation of the polymer, as pointed out by Kim et al. [8]

According to the TGA results, we performed thermal imidization reaction of CoPA-8-5/5 at the temperature range of $200-350^{\circ} \mathrm{C}$. Typical example of FT-IR spectrum after the thermal imidization is shown in Fig. 2c. By using the same manner described in the previous paper $[1,6]$,

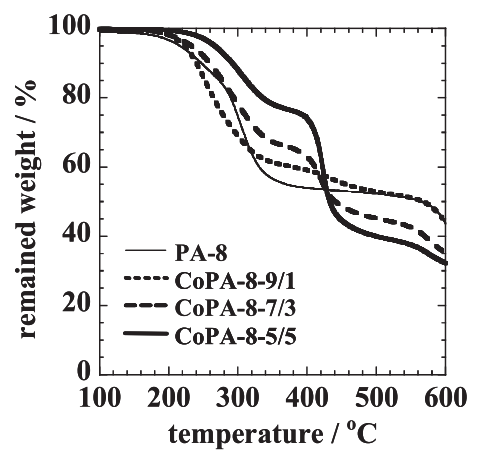

Fig. 4 TGA curves for PA-8 and various CoPA-8 measured at the heating rate of $10^{\circ} \mathrm{C} / \mathrm{min}$.

degree of imidization $\left(\alpha_{\text {imide }}\right)$ and fraction of the remained alkyl chains $\left(\alpha_{\text {alkyl }}\right)$ were evaluated from IR peaks at $1778 \mathrm{~cm}^{-1}$ (imide I) and $2922 \mathrm{~cm}^{-1}$ (C-H stretching), respectively, with using the peak for aromatic ring $\left(1515 \mathrm{~cm}^{-1}\right)$ as internal reference. Therefore, if the imidization reaction and removal of octanol progressed completely, both of $\alpha_{\text {imide }}$ and $\alpha_{\text {alkyl }}$ will be ca. 0.5 .

In Table $1, \alpha_{\text {imide }}$ and $\alpha_{\text {alkyl }}$ values for PA-8 and CoPA$8-5 / 5$ imidized thermally at various temperatures are compared. In the case of PA- 8 imidized at $250^{\circ} \mathrm{C}$, the reaction was almost finished and $70 \mathrm{~mol} \%$ alkyl chains were removed. Further decrease in $\alpha_{\text {alkyl }}$ was observed after imidization at higher temperature. In the case of CoPA- $8-5 / 5$ at $250^{\circ} \mathrm{C}, \alpha_{\text {imide }}$ and $\alpha_{\text {alkyl }}$ reached to the limited values expected from the copolymer composition. At higher imidization temperature, $\alpha_{\text {imide }}$ kept the value around 0.5 , however, $\alpha_{\text {alkyl }}$ decreased with elevating the temperature, and it was equal to zero when imidized at $350^{\circ} \mathrm{C}$. These results suggest that, the imidization and removal of the alkyl chains attached by ester linkage were almost completed at $250^{\circ} \mathrm{C}$, and at this temperature, the alkyl chains via ether linkage were still attached to the main chain. These alkyl chains were removed at higher temperature, probably because of thermal degradation of

Table 1 Numerical of results of $\alpha_{\text {imide, }}, \alpha_{\text {alkyl }}$, and $\rho_{\text {obs }}$ for PA- 8 and CoPA-8-5/5 imidized at various conditions.

\begin{tabular}{|c|c|c|c|c|c|c|c|c|c|}
\hline & \multicolumn{3}{|c|}{ condition } & \multicolumn{3}{|c|}{ PA-8 } & \multicolumn{3}{|c|}{ CoPA-8-5/5 } \\
\hline & solvent & $\begin{array}{c}\text { temp. } \\
\left({ }^{\circ} \mathrm{C}\right)\end{array}$ & $\begin{array}{l}\text { time } \\
(\mathrm{h})\end{array}$ & $\alpha_{\text {imide }}$ & $\alpha_{\text {alkyl }}$ & $\begin{array}{c}\rho_{\text {obs }} \\
\left(\mathrm{g} / \mathrm{cm}^{3}\right)\end{array}$ & $\alpha_{\text {imide }}$ & $\alpha_{\text {alkyl }}$ & $\begin{array}{c}\rho_{\text {obs }} \\
\left(\mathrm{g} / \mathrm{cm}^{3}\right) \\
\end{array}$ \\
\hline $\begin{array}{l}\text { Before } \\
\text { imidization }\end{array}$ & & & & & & 1.15 & & & 1.24 \\
\hline \multirow{4}{*}{$\begin{array}{l}\text { Thermal } \\
\text { imidization }\end{array}$} & - & 200 & 12 & 0.58 & 0.81 & 1.30 & 0.26 & 0.64 & 1.21 \\
\hline & - & 250 & 12 & 0.92 & 0.30 & 1.37 & 0.45 & 0.48 & 1.30 \\
\hline & - & 300 & 12 & 0.77 & 0.06 & 1.32 & 0.58 & 0.29 & 1.39 \\
\hline & - & 350 & 12 & 0.78 & 0.0 & 1.41 & 0.55 & 0.0 & 1.39 \\
\hline \multirow{3}{*}{$\begin{array}{l}\text { Chemical } \\
\text { imidization }\end{array}$} & pyridine & 80 & 24 & 0.76 & 0.43 & 1.33 & 0.59 & 0.75 & 1.28 \\
\hline & pyridine/toluene & 80 & 24 & 0.37 & 0.76 & 1.16 & 0.32 & 0.87 & 1.21 \\
\hline & pyridine/toluene & 80 & 96 & 0.53 & 0.62 & 1.26 & 0.43 & 0.73 & 1.28 \\
\hline
\end{tabular}


the ether bond.

In Fig. 5, WAXD photographs for PA-8 and CoPA$8-5 / 5$ imidized at various temperatures are compared. In CoPA-8-5/5, even after the complete imidization at $250^{\circ} \mathrm{C}$, the innermost reflection assigned to the layered structure was still observed as shown in Fig. 5d. However, in PA-8 imidized at the same temperature (Fig. 5b), the reflection from the layered structure disappeared and the reflection assigned to the PPPI crystallite was observed as indicated by the arrow. At $300^{\circ} \mathrm{C}, \alpha_{\text {alkyl }}$ value was 0.29 for CoPA-8$5 / 5$, due to the removal of some alkoxy groups by thermal degradation. WAXD pattern for this sample, however, still revealed a broad but distinct reflection at the smaller angle region as shown in Fig. 5e. It should be noted that the position the reflection was almost unchanged. Therefore, the layered structure was fairly remained even after $70 \%$ alkyl chains were removed. In Fig. 5e, weak reflection corresponds to PPPI crystalline lattice are shown, however, the tendency of PPPI segregation was much weaker than that for PA-8.

Solid-state chemical imidization was also performed for CoPA-8-5/5 according to the methods described in the previous paper $[1,6]$. Numerical results of $\alpha_{\text {imide }}$ and $\alpha_{\text {alkyl }}$ after various chemical imidization conditions are also summarized in Table 1. WAXD photographs for these chemically imidized CoPA-8-5/5 revealed similar results with those for thermal imidization, i.e., even after progress of the reaction, the innermost WAXD reflection was still intense and the reflection from PPPI crystallite was weak (photographs are not shown).

In Table 1 , evaluated density ( $\rho_{\text {obs }}$ ) values for the

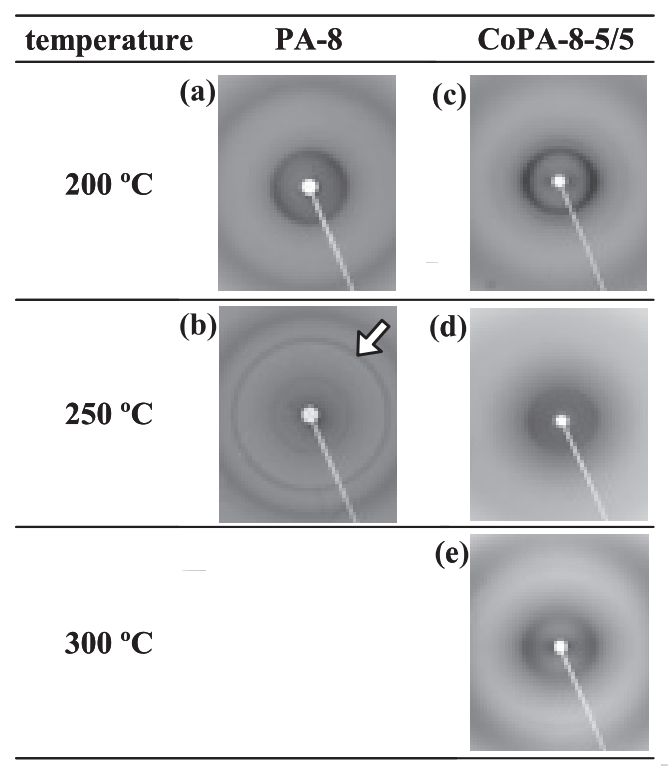

Fig. 5 WAXD photographs for PA- 8 and CoPA-8-5/5 imidized at various temperatures as indicated. imidized samples are also listed. In CoPA-8-5/5, when the extent of imidization reaction was ca. $50 \%$, i.e., $\alpha_{\text {imide }} \approx$ 0.25 derived by thermal imidization at $250^{\circ} \mathrm{C}$ or chemical imidization in the mixed solvent for $12 \mathrm{~h}, \rho_{\mathrm{obs}}$ was obtained as $1.21 \mathrm{~g} / \mathrm{cm}^{3}$. This value was smaller than $\rho_{\text {obs }}$ for CoPA-8-5/5 before imidization. On the other hand, in the case of PA- $8, \rho_{\text {obs }}$ for all the imidized samples were larger than that for PA- 8 . The decrease in $\rho_{\text {obs }}$ at the beginning of the reaction in CoPA-8-5/5 suggests that the layered structure was stably maintained even after the removal of some alkyl chains. However, the density became larger and larger by further progress of imidization.

\section{Discussion}

Above experimental results suggest that the alkyl chains attached by ether linkage were effective in order to maintain the layered structure and to prevent the PPPI segregation during the imidization. Here, we discuss the role of the alkoxy chains in the imidization reaction.

Possible structure model for $\alpha_{\text {alkyl }} \approx 0.5$ with keeping the repeating distance of the layered structure are schematically illustrated in Fig. 6, in which the main chain and side chain are represented by rectangle and wavy line, respectively. Some of these figures were already shown in Fig. 9 of Part I [1]. Fig. 6c shows an extreme case of Fig. 6b, i.e., the imidization and segregation of main chains occur locally in the sample and the layered structure is maintained in the unreacted area. In PA-8, as pointed out in Part I [1], the imidized polymer chains had tendency to segregate to form PPPI crystalline lattice, so the models in Fig. $6 \mathrm{~b}$ or $6 \mathrm{c}$ were plausible. On the other hand, in CoPA-8-5/5, a half of alkyl chains were remained with randomly attaching to the main chain when $\alpha_{\text {imide }} \approx 0.5$. Therefore, the models in Fig. $6 \mathrm{~b}$ and $6 \mathrm{c}$ were impossible, and that in Fig. 6a possibly occurred. As depicted in Fig. 6a, the randomly remained alkyl chains might effectively restrict the segregation of main chains.

Additionally, in CoPA-8-5/5, the main chain after the complete imidization can be regarded as poly(amideco-imide) as shown in Fig. 1. As pointed out by Hasegawa et al. [9], stiff polyimide chains have strong tendency to spontaneous molecular orientation during the thermal imidization, which was interpreted as a cooperative phenomenon because the neighboring chains promote the molecular orientation each other. The segregation of PPPI in the imidization of PA- 8 with destructing the layered structure may be explained by this 


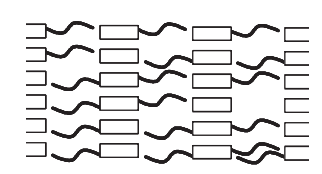

(a)

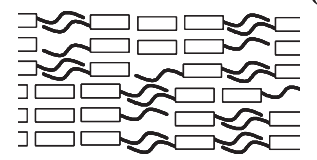

(b)

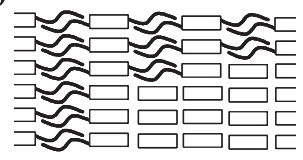

(c)
Fig. 6 Plausible structure models for PA-8 and CoPA8-5/5 after imidization. Detailes are described in the text.

cooperative phenomenon. In the case of CoPA- 8 , finally derived poly(amide-co-imide) was less stiff than PPPI, and this molecular flexibility will restrain the spontaneous orientation as well as the destruction of the main-chain segregated layer.

$\alpha_{\text {alkyl }}$ value of CoPA-8-5/5 after thermal imidization at $300^{\circ} \mathrm{C}$ suggested that some octyloxy groups were decomposed at this temperature. The WAXD pattern for this sample (Fig. 5e) indicated that the segregation of main chains with destructing the layered structure was fairly restrained. As can be supposed from Fig. 1, the imidization will accompany a drastic change in molecular structure at the terephthaloyl unit, which will disturb the molecular orientation of the main chain. On the other hand, the removal of alkyl chains by thermal degradation occurs after the imidization was completed. It is not clear how the chemical structure changes by the thermal decomposition, however, the molecular orientation may be less influenced than the imidization reaction. This difference in a mechanism of alkyl chain removal may be one of the reasons that the layered structure in CoPA-8 was more stably maintained than PA-8.

\section{Concluding remarks}

Thermal and chemical imidization were performed for copolyamide CoPA-8, in which some alkyl side chains were attached to the terephthaloyl unit by ether linkage, and the results were compared with homopolymer PA-8. The obtained conclusions are listed as follows.

1. CoPA- 8 was indicated to form the layered structure.

2. TGA curves for CoPA-8 exhibited two-step weight reduction, suggesting the imidization reaction and subsequent thermal decomposition of the octyloxy group.

3. Even after the imidization of CoPA-8-5/5 at $300^{\circ} \mathrm{C}$ and $\alpha_{\text {akyl }}$ became less than 0.3 , the innermost WAXD reflection was still recognized, suggesting that the alkyl chains attached by ether linkage were effective for maintaining the layered structure.

4. Effectiveness of the octyloxy groups for maintaining the layered structure was pointed out as follows. (1) Alkyl chains were remained randomly along the flexible main chain, which restrained the segregation of main chains. (2) Removal of the alkyl chains by thermal degradation occurred without disturbing the molecular orientation.

\section{Acknowledgement}

The authors gratefully acknowledge a financial support from a Grant-in Aid for Scientific Research on Priority Areas (B) "Novel Smart Membranes Containing Controlled Molecular Cavity" from the Ministry of Education, Culture, Sports, Science and Technology (Japan).

\section{References}

1. K. Inomata, S. Shimomura, M. Ogiso, H. Hasegawa, H. Sugimoto, and E. Nakanishi, Sen 'i Gakkaishi, 64, 273 (2008).

2. M. Ballauff, Angew. Chem. Int. Ed. Engl., 28, 253 (1989).

3. B. R. Harkness and J. Watanabe, Macromolecules, 24, 6759 (1991).

4. K. Inomata, Y. Sasaki, and T. Nose, J. Polym. Sci., Part B, Polym. Phys., 40, 1904 (2002).

5. H. Takashima, S. Okamoto, H. Yoshimizu, and Y. Tsujita, J. Appl. Polym. Sci., 97, 1771 (2005).

6. K. Inomata, Y. Ozeki, S. Shimomura, Y. Sakamoto, and E. Nakanishi, J. Mol. Struct., 739, 117 (2005).

7. S. B. Damman, F. P. M. Mercx, and C. M. Kootwijk-Damman, Polymer, 34, 1891 (1993).

8. S. I. Kim, T. J. Shin, S. M. Pyo, J. M. Moon, and M. Ree, Polymer, 40, 1603 (1999).

9. M. Hasegawa, K. Okuda, M. Horimoto, Y. Shindo, R. Yokota, and M. Kochi, Macromolecules, 30, 5745 (1997). 